\title{
Integumentary Histology of the Amphibious Blenny, Isteblennius edentulus (Forester and Schneider, 1801)
}

\author{
Taher Ba-Omar and Maisoon M. Al-Riyami
}

Department of Biology, College of Science, Sultan Qaboos University, P.O.Box 36, AlKhod 123, Muscat, Sultanate of Oman, Email: taher@squ.edu.om.

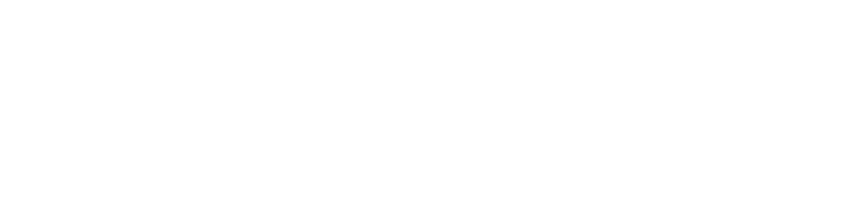

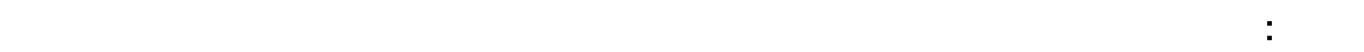

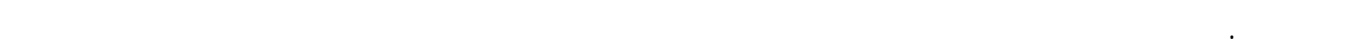

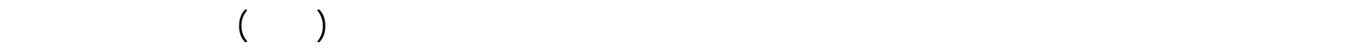

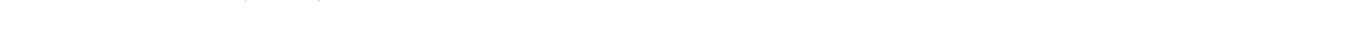

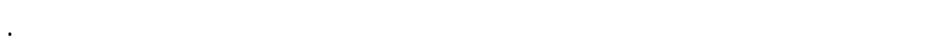

\begin{abstract}
The skin of the amphibious blenny, Istiblennius edentulus, was studied using both light and scanning electron microscopy. Rich vascularisation was found immediately below the epidermis and the dermis. Surface epithelial cells displayed microridges in a fingerprint-like pattern. It was speculated that this increased surface area may aid in the adhesion of mucous secretions as well as to increase the surface area for gas exchange. The number of pores on the dorsal side $\left(6.3 \times 10^{3}\right.$ per $\left.\mathrm{mm}^{2}\right)$ was significantly higher than that on the ventral side $\left(4.3 \times 10^{3}\right.$ per $\left.\mathrm{mm}^{2}\right)$. The thickness of the skin on the dorsal side was measured at $31.6 \pm 10.0 \mu \mathrm{m}$ and that on the ventral side was $32.9 \pm 7.8 \mu \mathrm{m}$.
\end{abstract}

KEYWORDS : Blenny; Istiblennius edentulus; pores; skin epithelia.

\section{Introduction}

Celeost fish, the most diverse group within the vertebrates, exploit a wide range of habitats. Some families such as the Blennidae (blennies), Pholidae (gunnels), Stichaeidae (prickle-backs), Gobiidae (gobies), 
Gobiesolidae (clingfishes) and Cottidae (sculpins) have colonized the intertidal zone (Gibson, 1986). These groups utilize the intertidal zone either as a primary habitat or as a feeding ground when it is submerged (Moyle and Cech, 1988).

In this environment they are exposed to daily variations in temperature, oxygen $\left(\mathrm{pO}_{2}\right)$, carbon dioxide $\left(\mathrm{pCO}_{2}\right), \mathrm{pH}$ and salinity (Bridges, 1988). They have therefore evolved a range of structural and physiological adaptations. These include small body size resistance to wave action scales firmly attached or totally absent, the development of mucus and the use of specialized pectoral fins for substrate attachment (Gibson, 1986).

Because gills collapse under their own weight in air, and so are not well suited to aerial respiration (Withers, 1992), structural adaptations have evolved to facilitate aerial respiration. These include modifications of the gills, the use of the skin as a gas exchange surface, special respiratory structures in the mouth and gut and, also, true lungs (Moyle and Cech, 1988). Some forms exploit the relatively high levels of oxygen in air to compensate for low levels in water.

Several histological studies have been conducted on the skin of various species of air-breathing fish (Mittal and Munshi, 1971; Brown et al. 1992; Al-Khadomiy and Hughes, 1988; Yokoya and Tamura, 1992; Suzuki, 1992 ; Zhang et al 2000 and Ba-Omar and Al-Riyami, 2007). In this study, we describe the skin structure of $I$. edentulus, using light and scanning electron microscopy and compare it to adaptations in fishes exploiting a similar niche.

\section{Materials and methods}

Specimens of Istiblennius edentulus (Figure 1) were collected from the rocky shores of the Gulf of Oman in Muscat, Oman and transported to the laboratory alive where they were kept in a saltwater aquarium. The fish were killed by freezing and then cut into three portions; front, middle and back. Each portion was then further divided into dorsal and ventral halves. Representative subsamples were fixed in $40 \%$ buffered formalin and processed for light microscopy. Other subsamples measuring $4 \mathrm{~mm}^{2}$ were fixed in $3 \%$ glutaraldehyde (two days) followed by a two-hour immersion in phosphate buffer ( $\mathrm{pH}$ 7.3) and then dehydration through an ethanol series. Tissue samples were then dried in a critical point drier (Samdri- PVT - 3B) and coated with gold using a JEOL JFC-1100 E ion sputter. The samples were examined with a JEOL JMS-840A Scanning Electron Microscope.

Using SEM micrographs exposed at a magnification of $\mathrm{x} 2000$, the number of pores on the surface of the epithelial cells per unit area, other than openings of mucous cells, was counted. The thickness of the skin on the dorsal and ventral sides was measured using the scale bar from the micrograph. An analysis of variance (ANOVA) was performed to detect significant differences in the number of pores on both dorsal and ventral sides and also to measure the thickness of the skin of both dorsal and ventral sides. Paired t-tests were performed to detect significant differences in the number of pores in the dorsal and ventral sides and the thickness of the skin. Data on the number of pores and the thickness of the skin were log transformed. Microsoft Excel was used for the statistical analysis.

\section{Results}

\subsection{Light microscopy}

The skin of I. edentulus does not possess scales. It displays the familiar three layers: epidermis, dermis and hypodermis (Figure 2). The epidermis consists of stratified squamous epithelium and contains large numbers of mucous cells which are spheroidal in shape (Figure 2). The dermis is made up of bundles of collagen fibers. The hypodermis lies between the dermis and the body musculature and consists of loose connective and adipose tissues (not visible in sections due to solution by xylene).

Blood capillaries, together with pigment cells, are seen throughout the integument. Pigment cells are elongated and have dendritic processes that radiate from the central cell body (Figure 2). The capillaries are more common on the dorsal side than on the ventral side of the fish. 


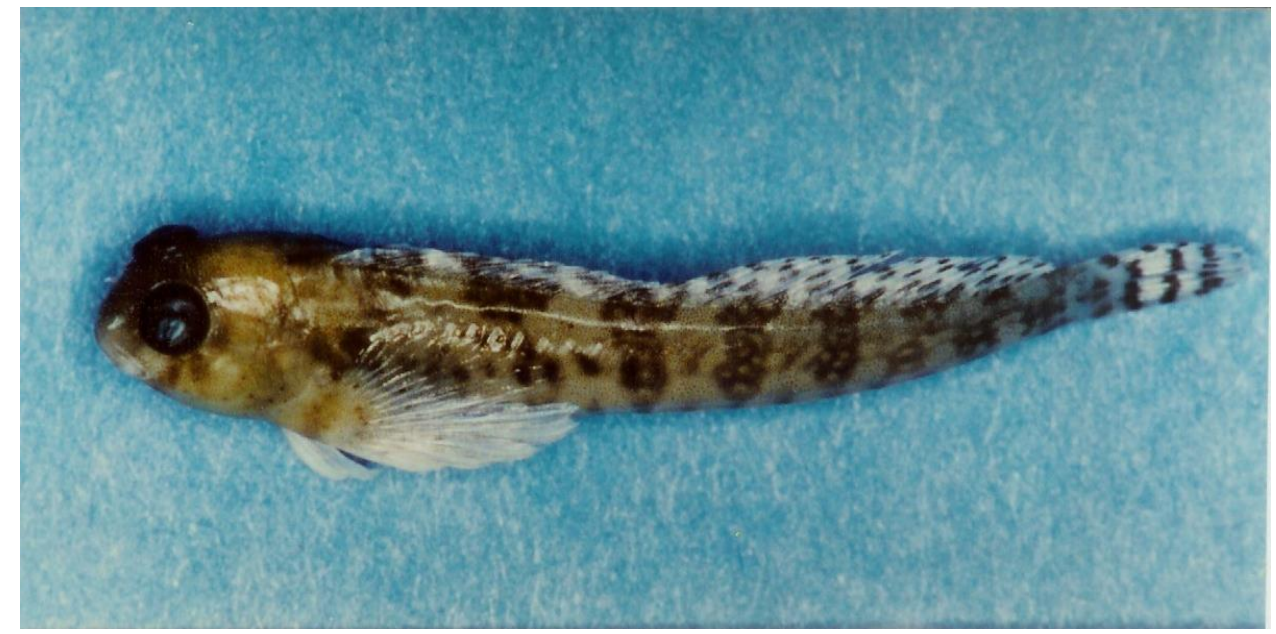

Figure 1. The amphibious blenny, I. edentulous.

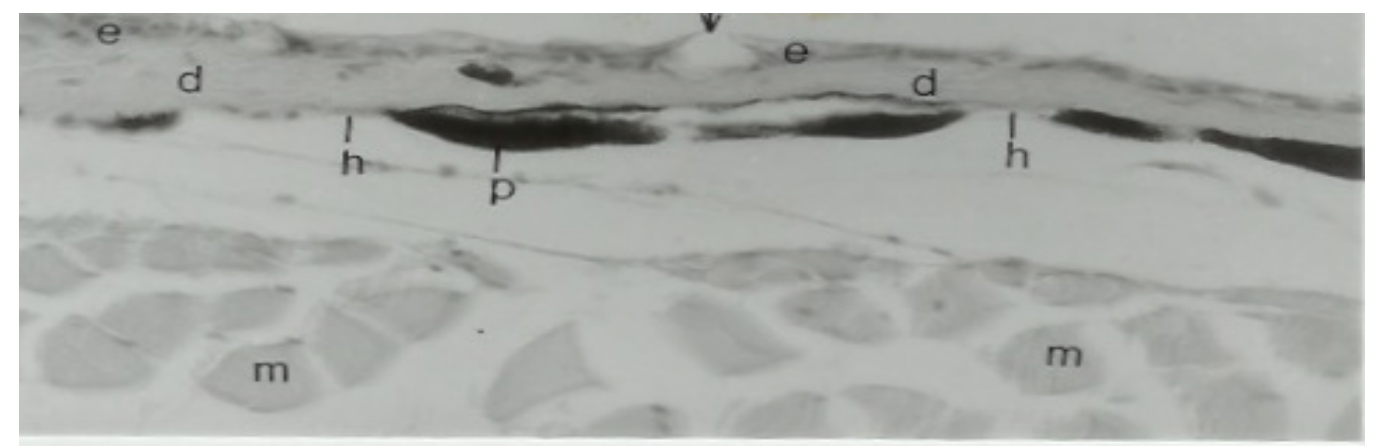

Figure 2. Light micrograph through the skin of I. edentulus from the dorsal side. epidermis (e), dermis (d), hypodermis (h), muscles (m), pigment cells (p), mucous cell (arrow). (H and E) X200.

\subsection{Scanning electron microscopy}

The epidermal cells that cover the skin surface possess closely-spaced microridges displaying a fingerprint-like pattern (Figure 3). The boundaries between the epidermal cells are clearly defined where several pores are visible at their junctions. In many cases, mucous cells can be seen in the vicinity of the pores. Other pores which extend deep into the integument were observed on the surface of epithelial cells (Figure 4). Unlike the light microscopic preparations, SEM micrographs clearly show pigment cells with their pigment granules. Blood capillaries are also clearly visible and can be seen running close to the epidermis and penetrating down through the dermis (Figure 5). 


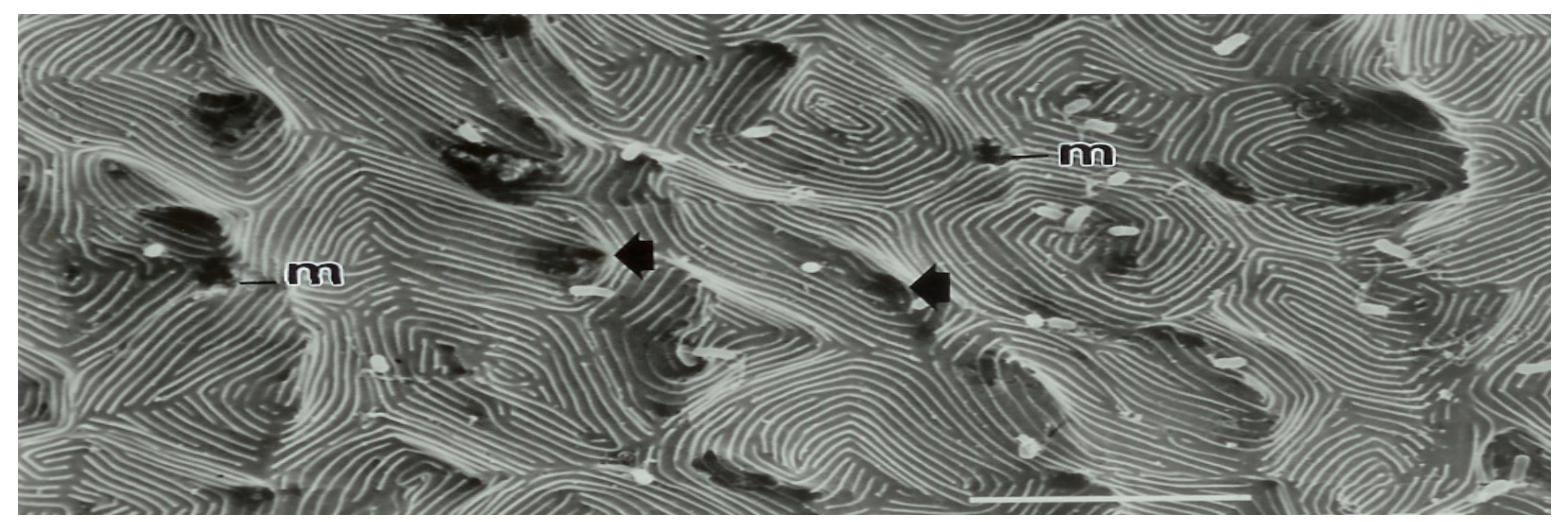

Figure 3. Scanning electron micrograph of the dorsal surface of the skin showing fingerprint-like appearance of the microridges. The opening of mucous cells (m) and the pores (arrows) are visible. Scale bar $=10 \mu \mathrm{m}$.

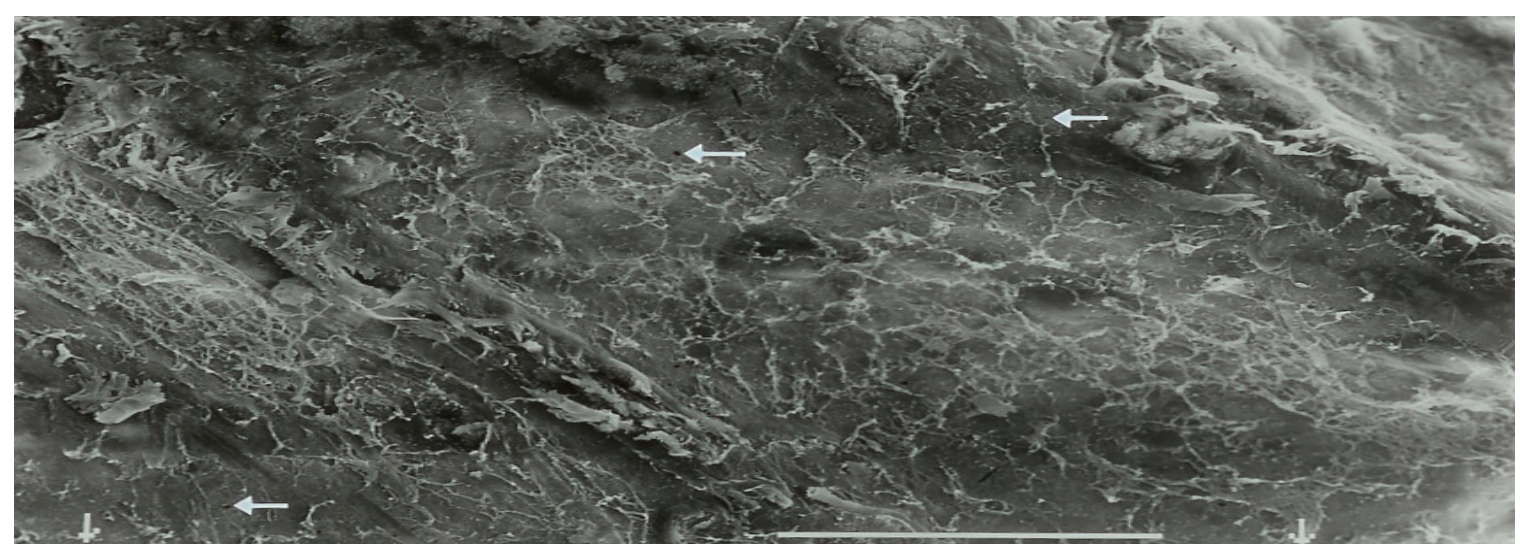

Figure 4. Scanning electron micrograph of the ventral surface of the skin showing pores (arrows). Scale bar = $100 \mu \mathrm{m}$ Not at all clear.

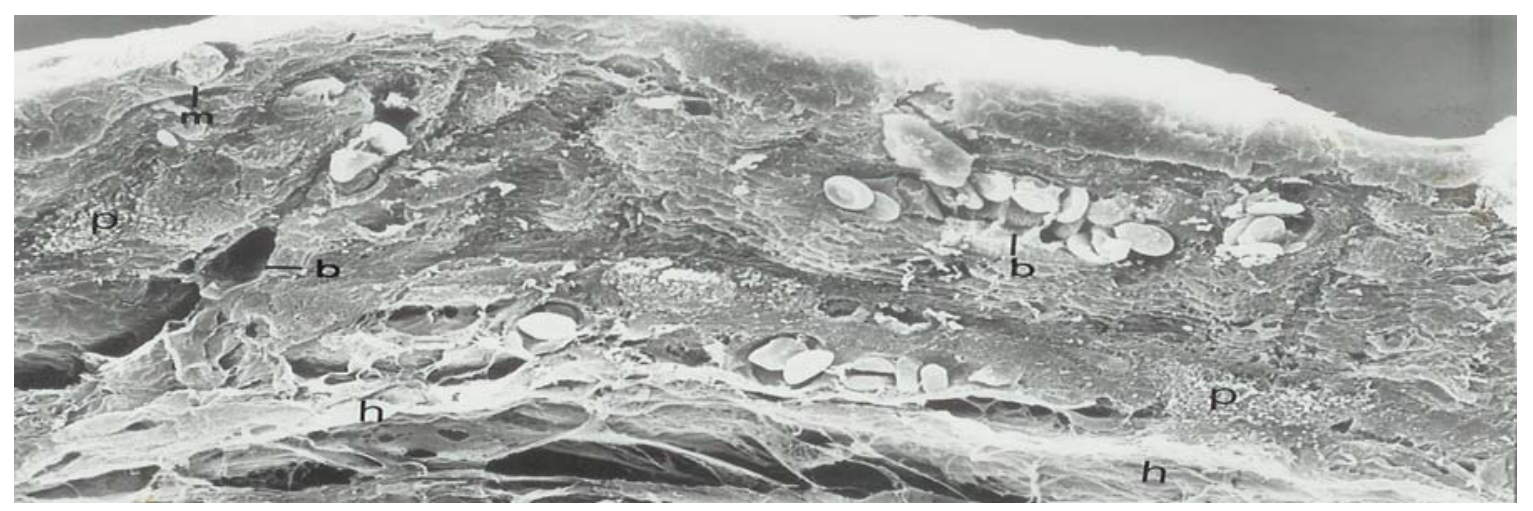

Figure 5. Scanning electron micrographs of the skin showing blood vessels (b), hypodermis (h), mucous cells (m) and pigment granules (p). Scale bar $=10 \mu \mathrm{m}$. 


\subsection{Measurements and statistical analysis}

Paired t- test showed that there is a significant difference in the number of pores in the dorsal and the ventral side of the body $(\mathrm{t}=3.519 ; \mathrm{P}=0.012)$. Pores are significantly more abundant in the dorsal side $\left(6.3 \times 10^{3}\right.$ pores $\left./ \mathrm{mm}^{2} \pm 0.8\right)$ than in the ventral side $\left(4.3 \times 10^{3}\right.$ pores $\left./ \mathrm{mm}^{2} \pm 1.1\right)$ (Table 1$)$.

Table 1. Maximum, minimum, mean and standard deviation with 95\% CL of the number of pores on the surface of the skin (x1000 per mm square) in the different parts studied, where $n=5$.

\begin{tabular}{|c|c|c|c|c|c|}
\hline Location & Dorsal & Ventral & Front & Middle & Back \\
\hline Maximum & 7.0 & 6.0 & 7.1 & 5.9 & 6.6 \\
\hline Minimum & 5.0 & 3.4 & 5.2 & 3.7 & 3.1 \\
\hline Mean & 6.3 & 4.3 & 6.1 & 5.1 & 4.8 \\
\hline SD & 0.8 & 1.1 & 1.1 & 0.8 & 1.4 \\
\hline
\end{tabular}

The average thickness of the skin on the dorsal side is $31.6 \mu \mathrm{m} \pm 10.0$ and that of the ventral side is $32.9 \mu \mathrm{m} \pm 7.8$ (Table 2). Anova and paired t-test have shown that there are no significant differences in the thickness of both the dorsal and ventral side $(\mathrm{F}=0.07, \mathrm{t}=0.335, \mathrm{p}>0.05)$

Table 2. Maximum, minimum, mean and standard deviation with 95\% CL of the thickness of the skin in the different parts studied, using SEM where $\mathrm{n}=5$.

\begin{tabular}{|c|c|c|c|c|c|}
\hline Location & Dorsal & Ventral & Front & Middle & Back \\
\hline Maximum & 48.0 & 43.3 & 41.7 & 51.5 & 42.7 \\
\hline Minimum & 20.9 & 21.8 & 25.1 & 18.5 & 19.0 \\
\hline Mean & 31.6 & 32.9 & 31.5 & 33.6 & 32.1 \\
\hline SD & 10.0 & 7.8 & 6.5 & 12.4 & 8.7 \\
\hline
\end{tabular}

\section{Discussion}

In amphibious fish, the integument must provide a viable interface between both air and water. While it has been indicated (Salih and Al-Jaffary, 1980) that the hypodermis is the principal layer of fish integument, this study has shown that the skin of the amphibious blenny, I. edentulus has a poorly developed hypodermis. In this species the epidermis is composed of stratified squamous epithelium and large numbers of mucous cells while the dermis is the dominant layer and contains bundles of layered collagen fibers. The hypodermis, which is the thinnest layer, is made up of loose connective tissues and adipose tissues.

Gas exchange in air breathing fishes generally does not occur across the gills but, across other vascularized surfaces, including the skin, buccal, branchial or opercular mucosa, stomach and intestine (Withers, 1992). The skin is particularly important in aerial respiration (Salih and Al-Jaffery, 1980) and is adapted by an increased density of cutaneous capillaries (Mittal and Munshi, 1971). Using such criteria, the air breathing fishes can be classified into three groups according to the structure of the skin: those in which the blood capillaries are subepithelial in position: those in which the capillaries are more numerous in the subepithelium and may even extend into the epithelium, and those in which the capillaries are mostly epithelial in position (Yokoya and Tamura, 1992). Mittal and Munshi (1971) suggested that the cutaneous blood capillaries are typically in the dermis and not the epidermis. The only vertebrates reported to have epidermal capillaries are some of the gobioid fishes and several semi-terrestrial amphibians (Kent, 1987).

Brown et al. (1992) showed the location of the capillaries just below the epidermis in the rock skipper Alticus kiri and suggested that they may perform an important function in gas exchange. The skin of I. edentulus 
is richly vascularized, and the blood capillaries are similarly present immediately below the epidermis and the dermis, thus also suggesting a role in gas exchange in this species. The most effective surface for gas exchange in the skin would seems to be the thinner and the more vascularized regions. Mittal and Munshi (1971) proposed that the capillaries of the skin, located within $500 \mu \mathrm{m}$ of the surface, are competent for the exchange of gases by diffusion. The skin of $I$. edentulus with a thickness of $18.5-51.5 \mu \mathrm{m}$ is likely to permit vascular gas exchange through diffusion. Since there is no significant difference in the thickness of the skin across the body, the entire skin of the fish would facilitate gas exchange with equal efficiency.

The surface view of the skin under SEM illustrated epithelial cells with invaginations and elevations that form fingerprint-like patterns. A similar pattern is seen in the skin of Coho salmon, Oncorynchus kisutch, and has been described as 'microridges' (Hawkes, 1974). Microridges were also reported in the gill filaments of the air breathing fish, Saccobamchus fossilis (Hughes and Mittal, 1973) and the swamp mud eel, Monopterus cuchia (Munshi et al. 1989). The probable function of microridges is to increase the surface area for gas exchange. However, Hughes and Munshi (1973) suggested that the microridges do not extend far above the general epithelial surface, and might well be more important for providing a surface of adhesion for the mucous layer.

There are two developmental pathways for the epidermis of vertebrates, one related to keratinization and the other to mucogenisis. This duality in developmental potential is open to environmental adaptation. Keratinization cell types usually occur predominantly in terrestrial animals, whereas mucous producing cells are found in amphibians and aquatic forms (Suzuki, 1992). The presence of large number of mucous cells in the epidermis of I. edentulus is an adaptation to its rocky habitat (Mittal and Banorjee, 1975). Since the skin is devoid of scales, unlike typical fishes, mucous cells serve to protect the skin against mechanical injury in the rock pool habitat. They also play a role in slowing desiccation by evaporation in air (Mittal and Banorjee, 1975). Furthermore, with respect to cutaneous respiration, the maintenance of wet surfaces is essential to preserve the functional morphology of diffusion membranes (Yokoya and Tamura, 1992). In I. edentulus mucous cells discharge their secretions onto the surface of the skin through openings located at the junctions of epithelial cells.

In addition to the openings of mucous cells, other pores were found to extend deep into the skin and may function to reduce the air-blood distance. The dorsal side of the fishes possesses larger number of pores and higher levels of vascularization than the ventral side. This suggests that higher rates of gas exchange may take place across the dorsal surface, which is consistent with it being the area most in contact with air.

Like blood capillaries, pigment cells are present just below the epidermis and the dermis. They have dendritic processes that extend from the central cell body. This organization enables changes in the colour such as are found in chromatophores. Consequently it can be deduced that pigment cells have both photoprotective and camouflage functions.

\section{References}

AL-KADHOMY, N.K. and HUGHES, G.M. 1988. Histological study of different regions of the skin and gills in the mudskipper, Boleophthalmus boddarti with respect to their respiratory function. J. Mar. Biol. Assn. $U K$, 68: 413-422

BA-OMAR, T.A. and AL-RIYAMI, M.M. 2007. Scanning electron microscopy of the fish Istiblennius edentulus skin . Microsc and Microanal 13: 282-283

BOND, C.E. 1979. Biology of Fishes. Saunders college publishing, New York. pp358-370.

BRIDGES, C.R. 1988. Respiratory Adaptation in Intertidal Fish. Am .J .Zoo, 28:79-96.

BROWN, C.R, GORDON, M.S. and MARTIN, K.L. 1992. Aerial and Aquatic Oxygen Uptake in the Amphibious Red Sea Rockskipper Fish, Alticus kiri (family Blennidae). Copeia. 4:1007-1013.

ECKERT, G., RANDALL, D., and AUGUSTIN,G. 1988. Animal Physiology, mechanisms and adaptation. 3rd ed. W.H Freeman and company, New york. pp483-496.

FISHELSON, L. 1975. Observations on the Behavior of the Fish Meiacanhus nigrolineatus Smith-Vaniz (Blenniidae) in nature (Red sea) and captivity. Aus. J. Mar. and Freshwater Res. 26: 329-341. 


\section{INTEGUMENTARY HISTOLOGY OF THE AMPHIBIOUS BLENNY}

GIBSON, RN. 1986. The Behaviour of Teleost Fishes. (ed. Pitcher, T.J.) Croom Helem ltd.,London. pp 388-406. GRAHAM, J. B. 1973. Terrestial Life of the Amphibious Fish Mnierpes macrophalus. J. Mar. Biol. 23: 83-91. HAWKES, IW. 1974. The Structure of Fish Skin, 1: General organization. Cell and Tiss. Res. 149:147-158.

HUGHES, G.M. and MUNSHI, I.S.D. 1973. Nature of the Air Breathing Organs of Indian fishes, Channa, Amphipnous, Clarias and Saccobamchus as shown by the electron microscopy. J. Zoo., London. 170: 245270.

KENT, G.C. 1987. Comparative Anatomy of the Vertebrates. $6^{\text {th }}$ ed. Times mirror/ Mosby college publishing, St. Louis. pp 138-173.

MITTAL, AK. and BANERJEE, T.K. 1975. Histochemistry and the Structure of the Skin of a Murrel, Channa striata. 1: Epidermis. Can. J. Zoo. 53: 833-843.

MITTAL, AK. and MUNSHI, I.S.D. 1971. A Comparative Study of the Structure of the Skin of Certain Airbreathing Freshwater Teleosts. J. Zoo. 163: 515-532.

MOYLE, P.B and CECH, II. 1988. Fishes: An Introduction to Icthyology. $2^{\text {nd }}$ edition Prentice-Hall, Inc. New Jersy. P45.

MUNSHI, I.S.D., HUGHES, G.M., GEHR, P. and WEIMBEL, E.R. 1989. Structure of the Air Breathing Organs of a Swamp Mud Eel Monopterus cuchia. Japan J. Icthyol. 35: 453-465.

SALIH, M.S. and AL-JAFFARY, A. 1980. Morpholgical Study of Boleophthalmus dentus, with reference to its feeding habits, 1:Habitat, External Features and Integument. Bull. Biol. Res. 149: 147-158.

SUZUKI, N. 1992. Fine Structure of the Epidermis of the Mudskipper, Periophthalims modestus (Gobiidae). Japan J. Icthyol. 38: 379-395.

WITHERS, P.C. 1992. Comparative Animal Physiology. Saunders College Publishing, New York. pp 608-614.

YOKOYA, S. and TAMURA, O.S. 1992. Fine structure of the skin of the amphibious Fishes, Boleophthalamus pectinirostris and Priophthalmus cantonensis, with special reference to the location of blood vessels. $J$. Morphol. 214: 287-297.

ZHANG, J., TANIGUCHI, T., TAKITA, T. and ALI, AB. 2000. On the epidermal structure of Boteophthalmus and Scartelaos mudskippers with reference to their adaptation to terrestrial life. Ichthyol. Res., 47(4): 359-366.

Received 6 May 2008

Accepted 29 June 2009 